\title{
0 perfil do professor de Geografia dos colégios estaduais da cidade de Irati - PR
}

\section{The profile of Geography teachers from public state schools in Irati - PR}

\author{
Haroldo José Andrade Mathias \\ Wanda Terezinha Pacheco dos Santos
}

\begin{abstract}
Resumo: Conhecer, de maneira mais ampla possível, o campo de trabalho do professor e suas interdependências com o campo pessoal, econômico, social e político contribui para que a escolha profissional seja consciente, evitando frustrações futuras. Considerando que o curso de Geografia da Universidade Estadual do Centro-Oeste, campus de Irati, se constitui sob a forma de licenciatura, torna-se oportuno extrapolar as fronteiras da sala de aula e verificar, em campo, qual o perfil do professor de geografia que atua nos colégios estaduais da cidade. Nesse contexto, a investigação de algumas das características da função docente em termos de conteúdo, contexto e expectativas pessoais também se reveste de considerável importância. Para tanto, além de uma abordagem bibliográfica, verificou-se através de questionários as especificidades inerentes à realidade local, as quais permitiram uma aproximação do perfil profissional dos professores atuantes, das relações de trabalho e das políticas voltadas à educação, das perspectivas e dificuldades da carreira e também dos reflexos que tal contexto gera na relação de ensino-aprendizagem.
\end{abstract}

Palavras-chave: Perfil. Professores. Irati. Geografia.

Abstract: Knowledge about teachers' working context and their interrelations with the personal, economic, social and political aspects contributes to a conscious choice, avoiding future frustrations. The Geography teaching degree at the Universidade Estadual do Centro-Oeste, (State University of the MidWest), campus of Irati, considers important to go beyond the boundaries of the classroom and know the profile of Geography teachers who work in public state schools in Irati. It is also important to understand some of the characteristics of the profession in terms of content, context and personal expectations of future teachers. The study included a literature reviews and by means of questionnaires it was possible to understand the specific local conditions, allowing the determination of the professional profile of inservice teachers, labor relations and policies related to education, the prospects and difficulties of the career and also the consequences of this context to the teaching-learning relationship.

Keywords: Profile. Teachers. Irati. Geography.

\section{Introdução}

Torna-se mais lógico optar ou não por determinada profissão e, quando atuando nela, agir com eficácia e qualidade na consecução dos objetivos, quando se tem, além das habilidades e conhecimentos necessários para exercê-la, consciência das dificuldades, das necessidades, das potencialidades e motivações daqueles que atuam em tal área.

\footnotetext{
* Graduando da UNICENTRO. E-mail: andradeadm@yahoo.com.br

* Undergradute student at the University of the Center West - UNICENTRO. E-mail: andradeadm@yahoo.com.br

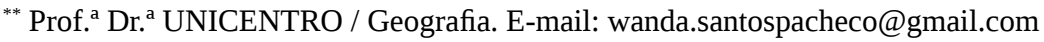

** Professor at the University of the Center West - UNICENTRO. E-mail: wanda.santospacheco@gmail.com
} 
Conhecer o campo de trabalho, de maneira mais ampla possível, e suas interdependências com o campo pessoal, econômico, social e político contribui para que a escolha seja consciente, evitando frustrações futuras, bem como possibilita aos professores que já atuam avaliar criticamente o cenário onde ocorre sua atuação.

Diante disso, busca-se conhecer o perfil dos professores de geografia dos colégios estaduais do município de Irati - PR, dentro de uma perspectiva espaço-temporal específica, compreendendo as características e perspectivas da carreira.

O contexto analisado objetivará também fornecer subsídios para se analisar os reflexos das variáveis levantadas na relação ensino-aprendizagem, permitindo comparar e aprimorar as variáveis que trazem resultados satisfatórios ao objetivo final dos colégios, que é o ensino.

O caráter dinâmico e específico das informações também se sustenta no fato de que o contexto de trabalho dos professores é passível de alterações segundo a dinâmica dos objetivos profissionais de cada um, pela busca por cursos de qualificação, pelo tempo de trabalho, pelas mudanças nos regimes de trabalho, pelos novos recursos e novas formas de ensinar, que exigem, sobretudo, a adaptação do professor.

É possível também, através da análise do perfil do professor de geografia, esboçar comparações com o perfil de professores de outras áreas do conhecimento, gerando espaço para investigações dos motivos das semelhanças e diferenças existentes. Um cotejamento com a realidade nacional também se torna possível, principalmente para ponderar as diferenças provenientes das muitas especificidades regionais, culturais e econômicas do Brasil, o que muitas vezes, faz com que o perfil do professor brasileiro, obtido por médias, não corresponda ao perfil do professor de determinada região tomada isoladamente.
A partir do conhecimento das relações de trabalho, das expectativas e frustrações dos professores, pode-se promover uma política de valorização da classe, de investimentos em recursos físicos e materiais. Pode-se também, no âmbito escolar, fomentar mecanismos que melhorem a motivação funcional e proporcionem melhor adaptação e autonomia ao professor, gerando como consequência um clima de trabalho agradável e produtivo, que, certamente, irá refletir-se no objetivo principal, que é a aprendizagem dos alunos.

\section{Exemplos de perfis profissionais de professores atuantes em outras realidades}

Souza et al. (2005) apresentam uma investigação acerca do perfil de professores de geografia do ensino fundamental da rede pública de educação do Estado de Goiás. Tanto os resultados dessa investigação podem ser comparados em alguns pontos, como ela pode servir de roteiro para a realização desta pesquisa.

Além disso, a observação da realidade das escolas públicas torna-se relevante, tendo em vista que, segundo dados nacionais do Instituto Nacional de Estudos e Pesquisas Educacionais Anísio Teixeira - INEP (2003), em torno de $80 \%$ dos professores de ensino infantil, fundamental e médio atuam em escolas públicas.

Da mesma forma, Martins (2005) apresenta uma pesquisa realizada pela Organização das Nações Unidas para a Educação, a Ciência e a Cultura - UNESCO, em 2004, a qual aponta o perfil do professor brasileiro e as perspectivas da profissão. Segundo essa pesquisa, mais de $82 \%$ dos professores se concentra nas instituições públicas no Brasil, fato esse que expõe a necessidade de esses 
profissionais, por serem a maioria, receberem maior atenção das políticas públicas.

Quanto a esse aspecto, é necessário considerar também o fato de que as escolas públicas - muitas com carência de recursos e estrutura e responsáveis por atender a diversos perfis de aluno, mais especificamente aqueles com menores condições socioeconômicas - têm o professor como agente de transformação social, o que justifica sua capacitação e melhores condições de trabalho.

Chedid (2009) argumenta que a escola é um dos primeiros espaços sociopolíticos reconhecidos pela Constituição Federal que são oferecidos à criança, sendo o professor um dos principais responsáveis por operar o processo que legitima a escola como local específico de cristalização do processo de ensino-aprendizagem, de socialização do saber e de acesso à cidadania.

Com relação à distribuição geográfica, Martins (2005) revela que 45,3\% dos professores da educação básica se concentram na região sudeste do Brasil, 25,1\% no nordeste, sendo que a região sul aparece na $3^{\mathrm{a}}$ posição, com 15,7\% dos professores. Em decorrência dessa distribuição, a relação média de professor-alunos, em nível nacional, é de 32 alunos para cada docente, sendo a menor proporção no sul, em torno de 26 alunos.

No que diz respeito aos aspectos financeiros, dados do Instituo Brasileiro de Geografia e Estatística - IBGE apontados por Martins (2005) revelam que a renda média do professor, apesar das ideias socializadas de desvalorização da profissão, é superior à renda média da população brasileira. A pesquisa também indica que professores que atuam nas capitais têm maior tendência a melhores salários.

Com relação à formação dos professores, a pesquisa comentada por Martins (2005, p.6) revela que " $80,3 \%$ dos professores que lecionam no ensino médio têm habi- litação superior com formação pedagógica e $60,3 \%$ dos professores que lecionam no ensino fundamental, têm habilitação superior com formação pedagógica”.

Sobre isso, o INEP (2002, p.26) ressalta que "de maneira geral observa-se que o nível de qualificação dos docentes tem melhorado muito nos últimos anos. Há, entretanto, de se avançar mais para o completo atendimento das metas do PNE”.

É interessante destacar que a Lei de Diretrizes e Bases da Educação Nacional LDBEN e o Plano Nacional de Educação PNE também apontam para as exigências e políticas sobre a formação inicial e continuada dos professores.

Embora o PNE mencione políticas de valorização do professor, como planos de carreira e promoções por mérito, dados do INEP (2003, p.11) revelam que "os cursos de graduação que oferecem licenciatura encontram-se entre aqueles com o maior número de vagas não preenchidas”.

Porém, não se pode desconsiderar o fato de que, segundo o INEP (2002), houve uma grande ampliação da oferta de cursos de licenciatura no Brasil, principalmente no setor público, chegando a um crescimento de 90\% nas matrículas entre os anos de 1991 e 2000, embora nem todos os concluintes se tornem professores, em decorrência de diversas variáveis. Além disso, não se pode considerar a demanda por professores de forma isolada da expansão da oferta do ensino.

Também segundo dados do Sistema Nacional de Avaliação da Educação Básica - SAEB de 2001 (INEP, 2002), a maioria dos docentes tem carga horária semanal superior a 20 horas, tendo como atividade principal o exercício do magistério. Nas séries finais do ensino fundamental e no ensino médio, em que 25\% dos profissionais têm atuação superior a 40 horas semanais, a situação é mais preocupante. 
Este fato provavelmente tem duas razões: 1) a falta de professores faz com que eles atuem em mais de um turno ou mesmo em mais de uma escola e, principalmente, 2) a necessidade de aumentar os rendimentos. Independentemente da causa, a dupla ou tripla jornada, com certeza, compromete o desempenho do professor. (INEP, 2002, p.45).

Com relação ao número médio de alunos por turma, embora haja diferenças regionais, diferenças entre séries e diferenças entre a rede pública e privada, o INEP (2002, p. 14) ressalta que "o número médio de alunos por turma pode ser considerado elevado em todos os níveis de ensino”.

Conclui-se também que a docência na educação básica é uma atividade na qual prevalece o gênero feminino, questão que não pode ser ignorada, bem como os incentivos financeiros, cujos dados apresentados mostram que "entre diversas profissões com nível de formação equivalente, o magistério é aquela que oferece os piores salários” (INEP, 2002, p.51).

A visão apresentada pelo INEP (2002, p. 03) traz uma reflexão sobre a importância do professor e das condições de trabalho deste profissional responsável por “educar mais de 57,7 milhões de brasileiros que estão matriculados desde a creche até o ensino superior de graduação”.

A situação refletida pelos números sugere que a decisão de ser professor, da forma que se apresenta, não tem se mostrado atrativa, em termos de mercado e condições de trabalho. Uma política de valorização do magistério contribuiria para resgatar o interesse e a motivação dos jovens em abraçarem essa carreira, que, em épocas passadas, ocupou um lugar de destaque. (INEP, 2002, p.03).

As diferenças regionais e as especificidades oriundas da disciplina lecionada também não podem ser desconsideradas nesse contexto, o que justifica conhecer a realidade do professor de Geografia dos colégios estaduais (séries finais do ensino fundamental e ensino médio) da cidade de Irati - PR.

\section{Metodologia e caracterização}

A pesquisa foi realizada no município de Irati, interior do Estado do Paraná, município localizado a 138 km de Curitiba, capital do Estado.

Figura 01 - Localização Geográfica da Cidade de Irati - Pr

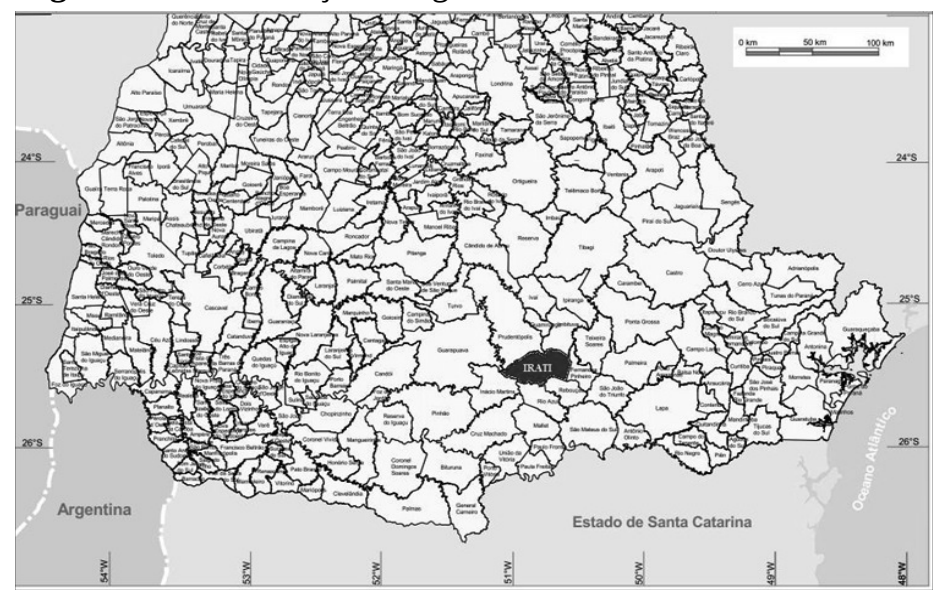

Fonte: http://www.ipardes.gov.br. 2010 
Segundo o site dia a dia educação, o município de Irati conta com 16 colégios estaduais, sendo que o questionário aplicado na pesquisada foi enviado via e-mail a todos esses colégios, solicitando o repasse aos professores da disciplina de geografia. A relação nominal de professores por colégio, disponível no site, revela que, em conjunto, eles contam com 24 profissionais em exercício na disciplina em questão.

Desta forma, o universo de pesquisa é de 24 professores e a amostra consiste no número de professores que devolveram os questionários devidamente respondidos, no caso, 9 deles.

Quanto à metodologia, a pesquisa é descritiva, pois, segundo Andrade (1999, p.106), “nesse tipo de pesquisa, os fatos são observados, registrados, analisados, classificados e interpretados, sem que o pesquisador interfira neles".

Para Carvalho (2006), a pesquisa descritiva utiliza informações ou eventos obtidos na própria realidade, tendo como uma de suas tarefas principais a coleta de dados, e apresenta como uma de suas particularidades o emprego de técnicas padronizadas, como a aplicação de questionários, entrevistas, observações, formulários, etc.

Quanto aos procedimentos, ou seja, quanto à forma pela qual se conduziu a pesquisa e se coletaram os dados, o trabalho utilizou-se de pesquisa bibliográfica e também de pesquisa de campo ou levantamento, através da aplicação de questionários.

Segundo Cervo e Bervian (1996, p.48), a pesquisa bibliográfica é o "meio de formação por excelência. [...] Constitui geralmente o primeiro passo de qualquer pesquisa científica”.

O segundo meio de coleta de dados utilizado no estudo foi a pesquisa de campo, que, de acordo com Andrade (1999, p.109), "é assim denominada porque a coleta de dados é efetuada em 'campo', onde ocorrem espontaneamente os fenômenos, uma vez que não há interferência do pesquisar sobre eles.”

Os níveis de ensino oferecidos nos colégios estaduais podem ser segmentados em duas categorias: séries finais do ensino fundamental e ensino médio. Entretanto, como muitos dos professores atuam nos dois segmentos, a pesquisa não fará nenhuma distinção a respeito disso na análise dos resultados. Além disso, considerando a pouca representatividade estatística da amostra, não se pretende extrapolar os dados para outras realidades ou casos. As análises limitam-se ao grupo efetivamente pesquisado.

A característica do questionário, com perguntas fechadas, também não gera a possibilidade de o professor expressar suas opiniões ou justificativas sobre os fatos, o que justifica a abordagem predominantemente descritiva do trabalho.

\section{Discussão dos resultados}

\section{a) Perfil dos professores}

Através dos dados obtidos com a aplicação dos questionários no $2^{\circ}$ semestre de 2010, devidamente respondidos por 9 professores de Geografia da rede estadual de ensino do município de Irati, constata-se que $56 \%$ deles são do sexo feminino e $44 \%$ do sexo masculino.

Assim, percebe-se que há uma integração do profissional masculino na área de docência, sugerindo que a escolha pelos cursos de licenciatura e o acesso ao mercado de trabalho nesse campo relacionam-se com as mudanças socioculturais e econômicas da época, congruente com o que 
apontou a pesquisa do INEP (2002). Porém, para o Ministério de Educação e Cultura MEC (2009) tal situação ocorre com maior frequência à medida que se avança para as séries finais do ensino fundamental e para o ensino médio, sendo que nas séries anteriores predominam as mulheres.

Dados do MEC (2009), decorrentes do censo escolar de 2007, indicam que 68\% dos docentes têm mais de 33 anos de idade e que 55\% estão na faixa de 30 a 45 anos. Com relação à idade dos professores de geografia pesquisados, a amostra permite inferir que a maioria (78\%) se encontra na faixa etária de 26 a 35 anos, gerando um perfil de professores um pouco mais jovem que a média nacional, a qual, segundo o MEC (2009), é de 40 anos para o ensino médio.

Gráfico 01 - Faixa Etária dos Professores Pesquisados

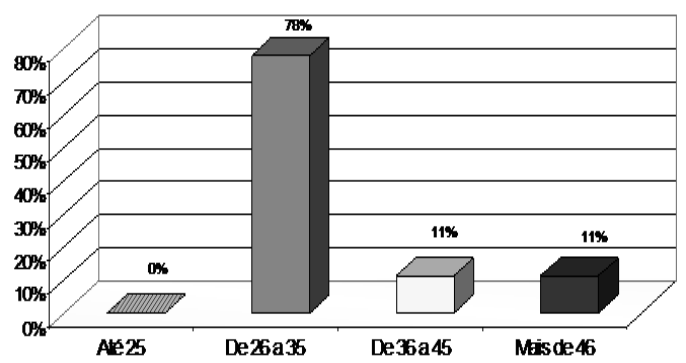

Fonte: Questionários aplicados aos professores de geografia de Irati - PR em 2010

Os dados acima apresentados se coadunam com os verificados na questão seguinte, que apresenta comparativamente o tempo de conclusão da graduação dos professores pesquisados e o seu tempo de atuação profissional.

Os resultados apontam que um percentual relevante (44\%) concluiu sua graduação entre 3 a 5 anos. Também se sobressai o percentual de professores (22\%) que concluiu a graduação há menos de 2 anos. Ou seja, pode-se afirmar que a maioria tem uma experiência de atuação inferior a 5 anos. A discrepância existente entre o tempo de graduação e o tempo de exercício da profissão (maior) se dá em virtude de que alguns dos professores possuem duas graduações e consideraram a última ao indicar o tempo de conclusão.

\section{Gráfico 02 - Tempo de Graduação e de Atuação Profissional}

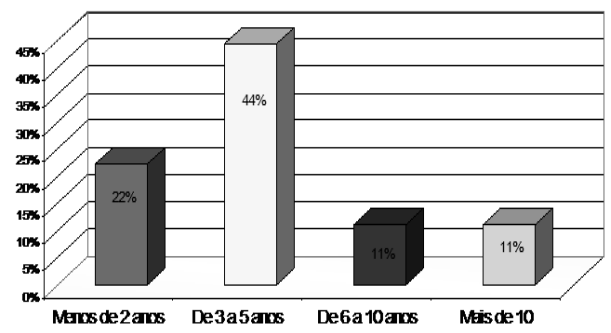

Fonte: Questionários aplicados aos professores de geografia de Irati - PR em 2010

\section{Condições de trabalho}

Como a pesquisa objetivou verificar não só o perfil pessoal dos professores, mas também algumas questões referentes às suas condições de trabalho, como o conteúdo e o contexto do cargo em que exercem suas funções, o número de colégios em que eles atuam foi também investigado.

Considerando que há uma dispersão de colégios, especialmente nas localidades rurais, gera-se a necessidade de deslocamento, o que acarreta gastos financeiros e riscos na locomoção para os professores, além do desgaste físico. Tal fato pode ter consequências na motivação e no desempenho do professor, refletindo-se no processo de ensino e aprendizagem.

Ressaltam Difini e Ribeiro (2002) que, embora sejam adotadas algumas medidas, a atenção aos recursos humanos no setor público tem deixado lacunas, em muitos ca- 
sos. Sobre esta questão, os dados da pesquisa de campo revelam que há uma significativa dispersão nas respostas, considerando que um número homogêneo de professores atua tanto em um, quanto em dois, três ou mais colégios.

Essa necessidade de deslocamento a outros colégios pode ser correlacionada com a próxima questão: a carga horária de atuação dos professores. Os dados coletados indicam que grande parte dos professores atua 40 horas semanais, o que contribui para que eles se vejam na necessidade de assumir aulas em diversos colégios para completar a carga horária de atuação.

Sobre a questão de trabalhar em dois turnos, dados do MEC (2009) para a realidade nacional apontam que o professor que atua em apenas um turno predomina em todas as etapas ou modalidades, chegando a $63,8 \%$. Isso torna mais evidente os resultados da comparação da carga horária com o vínculo empregatício, constatando-se que a maioria dos professores que atuam 40 horas são aqueles com contratos temporários.

Gráfico 03 - Carga Horária X Vínculo Empregatício

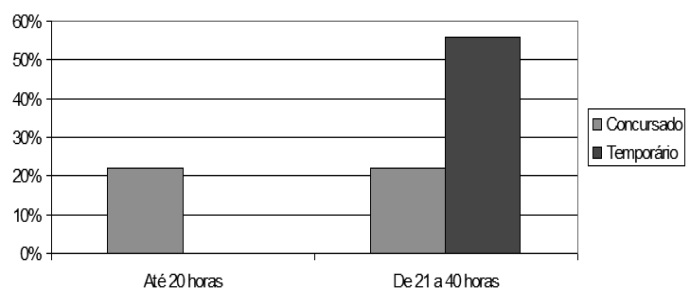

Fonte: Questionários aplicados aos professores de geografia de Irati - PR em 2010

É importante que a carga horária seja considerada de forma holística na interpretação das questões ulteriores, como a faixa salarial, a satisfação com o salário, o tempo disponível para leituras, a qualificação e preparação das aulas, o número de turmas e de colégios em que leciona, o desgaste físico do profissional, entre outras variáveis, tendo em vista que todas essas questões se interrelacionam.

Uma questão que se refere também ao desgaste do professor, e que influencia consideravelmente na relação ensinoaprendizagem, é o número de alunos por turma. A pesquisa buscou verificar quantos alunos há na turma mais numerosa em que o professor atua.

Os dados revelaram que o número máximo de estudantes por turma se enquadra na faixa de 34 a 37 alunos. Não obstante, há turmas que apresentam número superior a 42 alunos, situação que muitas vezes fica oculta nas simples análises de médias. Dados do MEC (2009) apontam que para a realidade nacional a média de alunos por turma é de 35 , o que permite afirmar que a realidade verificada pela pesquisa não constitui uma exceção neste quesito.

Outra situação relevante é a que se refere ao vínculo empregatício dos professores de Geografia que foram alvo da pesquisa. Os dados apontam que a maioria desses professores é contratada temporariamente através dos Processos Seletivos Simplificados, os chamados PSS. Na maior parte dos casos esses contratos possuem duração de um ano, podendo, conforme a necessidade do poder público, ser prorrogados por igual período.

Embora não sendo foco da pesquisa, uma análise superficial esclarece que esse vínculo - contrato temporário por meio dos PSS - por estar sujeito a interrupções, impede o acompanhamento da turma pelo professor, o que gera a necessidade de adaptação dos novos professores e dos alunos, prejudicando assim a relação ensino-aprendizagem.

Guimarães e Farias (2007, p.32) comentam que "para perder peso na área de educação, os governos passaram a valorizar os contratos temporários, pois eles 
representam menos custos fixos.” Assim, em alguns Estados, a força dos professores temporários é que mantém o sistema de ensino em funcionamento. Segundo os referidos autores, em 2007 havia 21\% de temporários no Paraná, $12 \%$ no Rio Grande do Sul, 55\% no Espírito Santo, 68\% no Ceará, chegando ao patamar de 75\% no Piauí.

Pelo fato de os professores contratados não terem a preferência na escolha de vagas, acabam atuando em vários colégios, como será demonstrado na sequência, o que se torna oneroso para eles em termos financeiros devido às locomoções. Além disso, esses professores gastam nas locomoções o tempo que poderia ser dedicado a outras atividades, e não contam com um plano de carreira.

Isso pode subjetivamente fazer com que eles não vislumbrem a continuidade de seu trabalho, podendo, inclusive, refletir-se na sua motivação e desempenho. "Como alguém pode cobrar o bom desempenho ou o comprometimento com o projeto pedagógico, se a pessoa está ali só por um tempo?” (SOUZA, apud GUIMARÃES; FARIAS, 2007, p.32).

É interessante ressaltar, porém, que a Lei 9394, de 20 de dezembro de 1996, que estabelece as Diretrizes e Bases da Educação Nacional, expressa:

Art. 67. Os sistemas de ensino promoverão a valorização dos profissionais da educação, assegurando-lhes, inclusive nos termos dos estatutos e dos planos de carreira do magistério público:

I - ingresso exclusivamente por concurso público de provas e títulos;

II - aperfeiçoamento profissional continuado, inclusive com licenciamento periódico remunerado para esse fim;

III - piso salarial profissional;
IV - progressão funcional baseada na titulação ou habilitação, e na avaliação do desempenho;

$\mathrm{V}$ - período reservado a estudos, planejamento e avaliação, incluído na carga de trabalho;

VI - condições adequadas de trabalho.

Ou seja, tanto a realidade apontada pela bibliografia consultada como o contexto verificado em Irati por meio dos dados coletados levam à constatação de que os preceitos básicos da legislação (os quais são instituídos visando à qualidade do ensino) são relegados a um segundo plano ou sequer são atendidos, dando-se prioridade aos aspectos econômicos, como a contenção de gastos, ou evidenciando a falta de planejamento por parte do Estado, o que o impele a contratar trabalhadores temporários para suprir as demandas.

O gráfico seguinte descreve visualmente a supremacia dos contratos temporários sobre o vínculo por concurso, conforme os dados obtidos com os professores de geografia dos colégios estaduais de Irati.

\section{Gráfico 04 - Vínculo Empregatício}

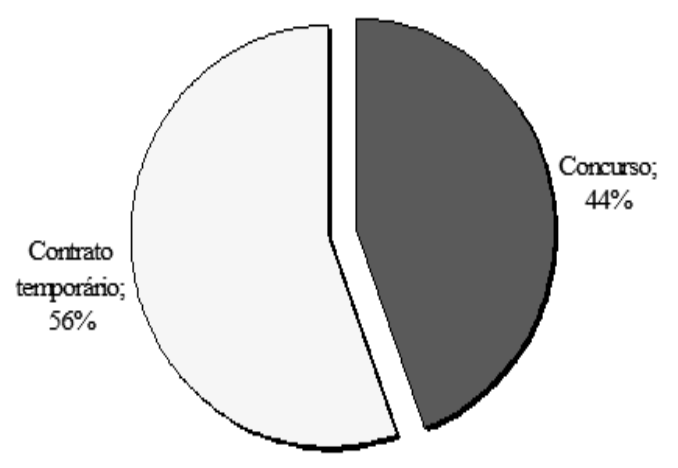

Fonte: Questionários aplicados aos professores de geografia de Irati - PR em 2010 
As informações apresentadas permitem inferir sobre a necessidade da abertura de concursos públicos que supram a demanda por professores efetivos e ponham fim a esse gargalo, o que constitui uma oportunidade para os recém-formados e outros graduados que ainda não tiveram a oportunidade de ingressar no magistério público.

Do ponto de vista pedagógico, um concurso contribui com a qualidade do ensino na medida em que os professores concursados poderão atuar em condições de trabalho mais propícias, tendo capacitações continuadas e gozando das prerrogativas dos planos de carreiras. Isso permite que eles concentrem seus esforços nas atividades de ensino-aprendizagem, acompanhando, inclusive, o desenvolvimento das turmas.

Com relação ao número de turmas em que os professores pesquisados lecionam, percebe-se que mais da metade deles atua em uma faixa de 5 a 10 turmas diferentes. Embora cruzando os dados se verifique que tanto temporários quanto efetivos atuam em poucas ou várias turmas de forma equilibrada, o mesmo não se pode dizer com relação ao número de colégios onde se dá essa atuação.

O resultado de um cruzamento da variável "vínculo empregatício” e "números de colégios em que atua" indica que grande parte dos professores temporários pesquisados (44\%) atua em três ou mais colégios. Os efetivos pesquisados, por sua vez, atuam em no máximo dois colégios.

Quanto à participação em cursos de capacitação, a maioria dos professores diz frequentar esses cursos com regularidade. Obviamente, seria oportuno verificar de forma mais objetiva o sentido do termo "regularidade” na concepção dos professores, obtendo-se assim uma média da quantidade efetiva de horas dedicadas à capacitação no decorrer do ano. Enfim, somente esta questão abre um leque imenso de questionamentos que poderiam ser elucidados com outras pesquisas, como, por exemplo: as vantagens obtidas e percebidas pelos professores com os cursos, os reflexos desses cursos no ensino-aprendizagem, a quantidade de horas ideal, a apreciação crítica dos conteúdos dos cursos e sua adequação ao contexto de atuação dos professores, etc.

As quatro questões seguintes procuraram avaliar as condições de trabalho dos professores pesquisados em relação aos seguintes fatores: recursos disponíveis, relacionamento com os alunos, relacionamento com os colegas de trabalho, remuneração e perspectivas de crescimento profissional.

Em relação aos recursos disponíveis para a execução do trabalho, as respostas orbitaram em torno de uma classificação intermediária, com 22\% dos professores apontando como regular e 78\% como boa, não havendo nenhuma classificação péssima ou ótima, ou seja, nos extremos do continuum.

O relacionamento com os alunos também se mostrou positivo, pois a maioria das respostas se concentrou na classificação boa (89\%), sendo que apenas $11 \%$ dos pesquisados consideraram esse relacionamento como ótimo. As classificações ruim e péssima não foram indicadas.

No relacionamento com os colegas de trabalho, o qual inclui a relação com a direção, os resultados são melhores: 44\% dos professores pesquisados classificaram esse relacionamento como ótimo e 56\% como bom, não surgindo nenhuma resposta que classificasse o relacionamento com os colegas de trabalho como péssimo ou ruim.

A condição mais preocupante, entre-tanto, ocorreu na avaliação das condições de trabalho referentes à remuneração e às perspectivas da carreira. Foi a única categoria da 
série de perguntas que avaliava as condições de trabalho em que apareceu a classificação péssima (11\%), com o agravante de que a classificação ótima não foi considerada por nenhum dos professores pesquisados.
O gráfico seguinte apresenta, de forma condensada e comparativa, as respostas obtidas nessas quatro questões.

Gráfico 05 - Avaliação Multifatores das Condições de Trabalho

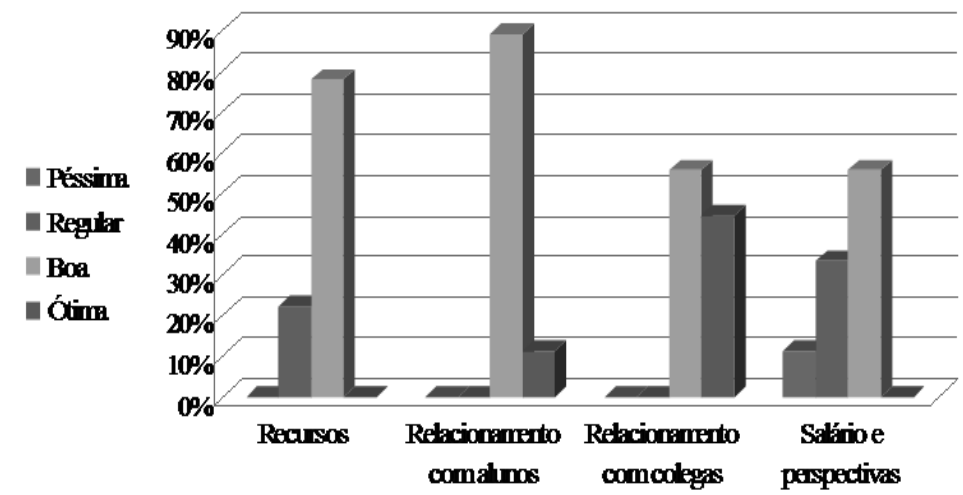

Fonte: Questionários aplicados aos professores de geografia de Irati - PR em 2010

Considerando que a remuneração e as perspectivas da profissão foram os itens de maior criticidade na avaliação dos professores, torna-se interessante conhecer, em termos quantitativos, a faixa salarial desses docentes.

Os dados revelam que $44 \%$ dos professores dizem receber entre $\mathrm{R} \$ 701,00$ a R\$ 1.200,00; outros 44\% apontam uma faixa salarial que varia entre R\$1201,00 a R\$ $1.800,00$ e apenas $11 \%$ têm um salário superior ao patamar de $\mathrm{R} \$ 1.800,00$. Calculando através de média ponderada o número de professores que ganham determinado salário (média do intervalo da faixa salarial) e atribuindo o peso de cada faixa ao número de professores correspondentes, tem-se que a média ponderada salarial do grupo pesquisado está em torno de R\$1289, 33.

O salário deve ser interpretado com base em diversos fatores, como nas diferenças de vínculo empregatício, no tempo de trabalho e principalmente na carga horária, pois $67 \%$ dos pesquisados trabalham 40 horas semanais. Entretanto, cruzando os dados relativos ao tempo de atuação com o salário recebido, verifica-se que não há uma correlação, pois professores que atuam de 6 a 10 anos possuem rendimentos semelhantes aos daqueles que atuam há menos de 2 anos.

Outro cruzamento de dados possível ocorre quando se verifica se, dado o grande número de professores com contrato temporário - o que segundo Guimarães e Farias (2007) tem como objetivo a redução de custos para o Estado -, os rendimentos dos professores temporários são inferiores aos dos professores efetivos. A análise dos dados referentes aos pesquisados revela que tanto efetivos quanto temporários mantêm uma significativa proporcionalidade nos rendimentos.

A partir disso é possível levantar duas hipóteses:

1) Considerando-se válida a afirmação de Guimarães e Farias (2007) para a 
realidade pesquisada, pode se inferir que há uma redução de custos na contratação de funcionários em outros pontos que não se referem aos rendimentos mensais pagos, mas à redução de investimentos em cursos de capacitação, ao pagamento de férias, entre outros gastos acessórios necessários para manter o professor em condições de atender às exigências do atual contexto socioeducacional.

2) Considerando-se que as atividades do professor não se encerram no término das aulas, devendo ele, além das capacitações, elaborar o planejamento de suas aulas, efetuar correções, realizar avaliações, etc., a necessidade de maior remuneração pode ser um dos fatores de influência na sobrecarga experimentada pelos professores em suas atividades.

Com relação à intensificação do trabalho docente, Fernandes (2010, p. 01) argumenta que as mudanças sociais e o reflexo de políticas públicas têm tornado o trabalho do professor mais desgastante, refletindo-se inclusive na saúde desse trabalhador. Outros fatores se incluem nessa intensificação, como o baixo prestígio social de sua função, atitudes de desrespeito dos estudantes e familiares em relação à autoridade do professor, e a indisciplina dos alunos.

Por outro lado, Lourenção (2010, p.1) reflete sobre o status do trabalho intelectual, como é o caso do trabalho docente, o qual costuma ser percebido como uma atividade própria “de integrantes da classe média, e que, ao priorizar o conhecimento, implica uma forte valorização simbólica, o que tradicionalmente trouxe certo status às profissões relacionadas a essas atividades”.

Com relação ao salário, apesar de os dados do INEP (2002, p.35) apresentados na introdução deste trabalho mostrarem que os professores possuem salários menores do que os de outras profissões equivalentes, para Guimarães e Farias (2007, p.37) “os professores ganham o mesmo que outras pessoas com mesmo grau de formação". Além disso, segundo os autores, em comparação com outros países, a remuneração média do professor brasileiro é 56\% mais elevada que a média nacional, enquanto que em países ricos é de 15\%. Para entender essa contradição é necessário levar em conta que em países desenvolvidos há uma menor desigualdade salarial entre as profissões, não indicando, efetivamente, que os professores têm uma remuneração menor em termos absolutos.

Outra questão diz respeito às desigualdades regionais no próprio território brasileiro, que, segundo Guimarães e Farias (2007, p.37), chegam a elevar ou reduzir quase quatro vezes o valor da hora trabalhada. Isso justifica, mais uma vez, a realização de uma pesquisa local que reduza as distorções geradas pelas especificidades regionais, as quais, em maior ou menor grau, afetam uma pesquisa mais abrangente.

Os pesquisados também foram indagados se atualmente tomariam a mesma decisão de optar pela licenciatura em geografia e dar aulas. Grande parte deles (78\%) respondeu que sim, enquanto $11 \%$ afirmaram que não repetiriam a escolha e os últimos $11 \%$ não responderam à questão. Esse é um indicativo interessante, pois apesar das dificuldades a profissão apresenta vantagens subjetivas que tornam a escolha recompensável, segundo a percepção de muitos pesquisados.

Obviamente, a motivação que define a escolha pelo trabalho docente não faz parte do escopo da pesquisa, mas provavelmente engloba fatores financeiros, a segurança e estabilidade no emprego, no caso dos concursados, a possibilidade de crescimento pessoal, a vocação, entre outras variáveis que merecem uma investigação voltada para esse fim. 
Com relação à dedicação exclusiva à carreira docente, $78 \%$ dos professores têm como única ocupação profissional lecionar, enquanto que $22 \%$ desempenham uma segunda atividade profissional, indicando como motivo para isso a necessidade de complementar a renda, a perspectiva insatisfatória quanto ao futuro profissional ou a falta de segurança com relação ao vínculo empregatício, no caso dos temporários.

Dadas as jornadas de 40 horas cumpridas pela maioria, o tempo gasto com deslocamento por aqueles que atuam em vários colégios, as atividades profissionais secundárias realizadas por alguns, considerou-se oportuno verificar junto aos pesquisados se eles dispõem de tempo para realizar atividades de leitura, pesquisa e qualificação. Sobre isso, 56\% dos pesquisados afirmam que têm tempo disponível, ao passo que 44\% dizem não ter.

Essa questão pode ser analisada considerando também o tempo que o professor diz ter disponível para a realização de seu planejamento. Segundo dados obtidos com a pesquisa, o tempo disponível médio utilizado para a elaboração dos planejamentos, desconsiderando o menor e o maior valor pelo seu alto grau de dispersão, é de 6 horas por semana, sendo que há professores que dedicam 2 horas semanais (limite inferior) a essa atividade e outros que dedicam 10 horas (limite superior).

A pesquisa também verificou o uso ou não das tecnologias da informação em sala de aula, exclusivamente no que se refere à disciplina de geografia, sem se ater aos objetivos ou esboçar críticas a sua eficácia, vantagens ou desvantagens. Os dados obtidos evidenciam que a maioria dos professores utiliza com frequência em suas aulas recursos multimídia ou de informática.

Isso demonstra uma preocupação dos professores em se manterem atualizados em relação às novas tendências da educação e às demandas sociais. Há de se considerar também nessa questão o perfil jovem dos professores pesquisados, sendo que a maioria tem idade inferior a 35 anos.

Considerando o atual contexto social, onde a mídia divulga diversos casos de violência, em suas diversas formas, contra o professor, julgou-se interessante verificar se os professores pesquisados já tiveram, no decorrer de sua carreira, algum sentimento de ameaça em decorrência do comportamento de seus alunos.

Para ilustrar a questão, segundo o site Jornal da Ciência, os dados revelados por uma pesquisa da Unesco realizada em 2003 apontam que mais de $50 \%$ dos professores afirmam haver casos de furtos nas escolas onde trabalham, 10\% conhecem casos de gangues ou tráfico nas instituições e 30\% já viram alunos portando algum tipo de arma. Estes dados são relevantes, pois é preciso considerar ainda que em muitos casos a violência impõe a lei do silêncio ou se assume a posição de que nada está acontecendo.

Mesmo considerando que a maioria dos professores (67\%) estava atuando há menos de 5 anos, quando foram questionados, esse sentimento de ameaça em decorrência do comportamento dos alunos existe, pois, conforme dados coletados, $44 \%$ dos professores já tiveram tal sensação.

Tais situações podem exercer influência nas perspectivas de futuro profissional dos professores, afetando tanto o recrutamento de novos professores quanto a procura por cursos de licenciatura.

A última questão ofereceu aos pesquisados a possibilidade de descreverem, de forma aberta, pelo menos dois pontos positivos e dois pontos negativos relacionados à docência em geografia. 
Entre os pontos positivos mais recorrentes está o fato de que a docência permite ao professor se manter atualizado, o que está em conformidade com as respostas dadas nas questões fechadas, as quais evidenciaram que a maioria dos professores participa com regularidade de cursos de capacitação e mais da metade considera ter tempo suficiente para leitura e pesquisa. Além disso, é importante lembrar que a troca de experiências e o relacionamento humano favorecem esse crescimento intelectual e profissional.

Entretanto, como critica Chedid (2009), sugestões teóricas, ações e projetos no sentido de promover o desenvolvimento cognitivo do aluno são comuns, o que é de importância inquestionável. Porém, é incomum esse mesmo grau de preocupação com o professor, o qual necessita de ferramentas para aprimorar seu conhecimento.

Como um dos aspectos positivos que surgiu diversas vezes e que aparenta motivar o trabalho dos professores pesquisados, está a contribuição com o desenvolvimento e formação dos estudantes. E entre outros pontos positivos no trabalho docente, que foram citados com frequência secundária, estão os relacionamentos interpessoais e o gosto pela disciplina e pelo trabalho docente. Afinal, como demonstrado anteriormente, $78 \%$ dos pesquisados disseram que repetiriam a sua escolha acadêmica e profissional.

Quanto aos pontos negativos apontados, com uma frequência próxima da unanimidade, foram elencadas as seguintes questões: muitos alunos por turma, a indisciplina dos alunos e a falta de materiais.

Com relação ao número de alunos, embora a pesquisa aponte que a maioria dos professores (66\%) leciona em alguma turma que conta com mais de 34 alunos, o quadro a seguir, apresenta o número médio de alunos no Paraná, na área de abrangência do Núcleo Regional de Educação de Irati e também no município de Irati.

Quadro 01 - Turmas e matrículas por unidade administrativa e modalidade de ensino - 2010

\begin{tabular}{|c|c|c|c|c|}
\hline & & A & B & $\mathrm{B} / \mathrm{C}$ \\
\hline Unidade Administrativa & Modalidade de Ensino & Turmas & Matrículas & $\begin{array}{c}\text { Média de } \\
\text { alunos por } \\
\text { turma }\end{array}$ \\
\hline \multirow{2}{*}{ Estado do PR } & Ens. Fundamental & 24223 & 708079 & 29 \\
\hline & Ens. Médio & 12584 & 359654 & 29 \\
\hline \multirow{2}{*}{ Núcleo Regional - Irati } & Ens. Fundamental & 486 & 14037 & 29 \\
\hline & Ens. Médio & 244 & 7044 & 29 \\
\hline \multirow{2}{*}{ Município - Irati } & Ens. Fundamental & 135 & 4018 & 30 \\
\hline & Ens. Médio & 71 & 2096 & 30 \\
\hline
\end{tabular}

Fonte: Síntese de dados do Portal Dia-a-dia educação

Tais dados permitem que se tenha uma visão mais global do tamanho das turmas, alvo de crítica tanto de professores quanto de estudiosos que buscam definir as melhores condições de ensino e o número ideal de alunos, o que se reflete na relação ensino-aprendizagem.
No que concerne ao comportamento e à disciplina dos alunos, de acordo com Zene (2003) não é possível considerar a indisciplina escolar como algo isolado, pois as causas são tanto intrínsecas quanto extrínsecas à escola. 
Para Pelt (1996, p. 14), citado por Zene (2008, p. 41),

os tempos mudaram, mas não as relações humanas que constituem as raízes da formação do caráter. Os filhos ainda precisam de pais porque as relações afetivas que mantém com eles desde o nascimento permitem que adquiram padrões que os tornarão seres normais. As crianças precisam de direção, disciplina, apoio e ânimo para crescer, amadurecer e tornarem-se pessoas independentes da família, adultos autônomos.

Essa questão remete a outro ponto também apontado como negativo pelos pesquisados: a omissão da família no acompanhamento escolar do aluno. Questões que se resumem na carência de materiais para utilização nas aulas também foram apontadas por diversos pesquisados como um dos pontos negativos. Secundariamente, surgiram questões como pouca hora atividade, defasagem salarial, falta de valorização da profissão e excesso de trabalho.

\section{Considerações finais}

O presente trabalho permitiu conhecer alguns traços do perfil dos professores de geografia dos colégios estaduais do município de Irati - PR, destacando-se o fato de que não há pretensão de que os resultados sejam generalizados para outras escalas de abrangência.

Ressalta-se que, entre os resultados obtidos, chama a atenção o número de professores com contrato temporário. Embora não seja uma exclusividade de Irati ou do Paraná, como apresentado em outras pesquisas, tal fato tem consequências nas relações de ensino-aprendizagem.
A especificidade desse vínculo profissional facilita a existência de lacunas na continuidade do processo de ensinoaprendizagem com a saída dos temporários ao término do contrato, além de trazer prejuízos educacionais inerentes ao acesso de profissionais com pouca experiência e sem perspectiva de continuidade de seu vínculo. Alia-se a isso a circunstância de que esses temporários, de modo geral, possuem uma carga horária de atuação de 40 horas e atuam em diversas escolas. Isso traz reflexos inclusive no aspecto pessoal desses professores, podendo contribuir para o aumento do desgaste físico, mental e dos níveis de estresse.

A pesquisa também aponta que esse contexto contribui para a significativa parcela de professores que dizem não ter tempo disponível para as atividades de leitura, pesquisa e qualificação, exigências indispensáveis para a preparação adequada das aulas como também para se manter apto a atender as exigências do atual contexto social, econômico, político no qual a educação se insere.

Como mais uma preocupação para os professores, dificultando que toda sua potencialidade seja direcionada à ação de ensinar, muitos desses profissionais, em algum momento, já se sentiram ameaçados pelo comportamento de alunos. Além dos prejuízos em termos de atuação profissional, o magistério como um todo acaba sofrendo com o desinteresse de novos estudantes aos cursos de licenciatura, como apontado pelo referencial teórico adotado. Dadas essas situações, pode haver tendências dos professores em exigir outras compensações, como elevações salariais, ou mesmo em se tornarem inseguros em sua atividade de ensinar.

Apesar disso, os professores tem se mostrado voltados à inovação em suas aulas. A grande maioria utiliza recursos 
multimídia e de informática com frequência, demonstrando estar acompanhando as mudanças impostas pela era da informação. Obviamente, nessa predisposição às mudanças pesa o perfil jovem dos professores pesquisados.

No campo financeiro, embora a profissão de professor esteja entre aquelas com menor salário para o grau de escolaridade - e considerando que nenhum dos professores considera sua remuneração como ótima e que quase a metade deles assinalou essa questão como péssima ou regular -, a pesquisa mostrou que apenas $11 \%$ dos professores pesquisados não repetiriam a escolha acadêmica e profissional que os levou à docência em geografia.

Desta forma, pode se inferir que, embora as questões objetivamente verificáveis, como remuneração, recursos disponíveis, segurança (tanto física quanto nas condições de trabalho), não sejam, em sua maioria, satisfatórias, há fatores de ordem subjetiva que motivam os professores ao exercício da docência.

A possibilidade de crescimento intelectual e atualização, a contribuição na formação de pessoas, dando um senso de valor ao trabalho, a qualidade dos relacionamentos interpessoais que a profissão permite, além do gosto pela disciplina e pelo trabalho podem ser considerados sob esta perspectiva, embora não se possam desconsiderar outros fatores não captados pela pesquisa.

Não obstante esta pesquisa tenha como diferencial o fato de apontar o perfil do professor de geografia específico dos colégios estaduais de Irati - livre dos desvios gerados pelas médias, que não levam em conta as amplas diferenças regionais de nível de ensino, entre outras - é preciso considerar que sua amostra é reduzida, o que gera a necessidade de que os resultados se refiram aos professores pesquisados, não havendo a pretensão de extrapolar para outros grupos a análise aqui realizada.

\section{Referências}

ANDRADE, M. M. Introdução à metodologia do trabalho científico. 4.ed. São Paulo: Atlas, 1999.

BARBOSA, S. J. A intensificação do
trabalho docente na escola pública.
Universidade de Brasília. Brasília: 2009 .
Disponível em: <http://bdtd.bce.unb.
br/tedesimplificado/tde_busca/arquivo.
php?codArquivo=5059> Acesso em: 20 de
Fevereiro de 2010 .

BRASIL. Lei 9394 de 20 de dezembro de 1996. Disponível em: http://www.planalto. gov.br/ccivil_03/Leis/L9394.htm. Acesso em: 22 setembro 2009.

CARVALHO, M. A. Pesquisa: conceitos e definições. Universidade de Brasília. Departamento de Ciência da Computação. Brasília, 2006. Disponível em: <www.pgsc. ufma. br/pesquisa $>$ Acesso em: 20 agosto 2010.

CERVO, A. L; BERVIAN, P. A. Metodologia científica. 4. ed. São Paulo: Makron Books: 1996.

CHEDID, E. O professor como agente essencial de transformação. Assembléia Legislativa do Estado de São Paulo. São Paulo: 2009. Disponível em: http://www. jusbrasil.com.br/noticias/1971130/opiniaoo-professor-como-agente-essencial-detransformacao.

DIFINI E; RIBEIRO E; RIBEIRO, C. D. R. Avaliação da satisfação dos técnicoadministrativos em uma instituição de ensino superior: um estudo de caso. Universidade Federal do Rio Grande do Sul. 
Porto Alegre: 2002. Disponível em <http:// www.lume.ufrgs.br/handle/10183/1693> Acesso em: 11 novembro 2009.

GUIMARÃES, A; FARIA, F. Uma profissão, várias realidades. Revista Nova Escola. Ano 22, n.201. Ed. Abril. 2007, p.26-37.

INEP - Instituto Nacional de Estudos e Pesquisas Educacionais. Estatísticas dos professores do Brasil. Brasília, 2003. Disponível em: http://www.inep.gov.br/download/ censo/2003/estati sticas_professores.pdf . Acesso em: 16 agosto 2009.

JORNAL DA CIÊNCIA. Professores apontam violência nas escolas. 2004. Disponível em: <http://www.jornaldaciencia.org.br/ Detalhe.jsp?id=21134> Acesso em: 27 julho 2008.

LORENÇÃO, F. G. Professores temporários e o trabalho docente. In: SEPECH - Seminários de Pesquisa em Ciências Humanas, 8, 2010. Anais... Disponível em: <http://www. uel.br/eventos/sepech/arqtxt/resumos-anais/ FernandaGLourencao.pdf $>$. Acesso em: 20 fevereiro 2010.

MARTINS, M. A. A agenda da educação nos tempos atuais: considerações sobre o cenário e as políticas de formação docente. Revista Iberoamericana de Educación, v.39/5, 2005. Disponível em: http://www.rieoei. org/deloslectores/1240Martins.pdf. Acesso em: 12 de agosto de 2009. Acesso em: 15 setembro 2009.

PARANÁ. Secretaria da Educação. Portal Dia-a-dia Educação. 2010. Disponível em: $<$ http://www.diaadiaeducacao. p r.gov.br/dia a di a / e s cola / index . php?PHPSESSID=2011072820581645> Acesso em: 10 setembro 2009.

PREFEITURA MUNICIPAL DE IRATI / SECRETARIA MUNICIPAL DE EDU-
CAÇÃO. Conheça seu município: história e geografia. Irati: 2001.

Professores apontam violência nas escolas. Jornal da Ciência. 2010. Disponível em: <http://www.jornaldaciencia.org.br/Detalhe.jsp?id=21134> Acesso em: 20 outubro 2009.

Secretaria de Estado do Planejamento e Coordenação Geral. IPARDES - Instituto Paranaense de Desenvolvimento Econômico e Social. Divisão política Paraná. 2010. Disponìvel em: <http://www.ipardes. gov.br/modules/conteudo/conteudo. php?conteudo=133> Acesso em: 27 janeiro 2011.

SOUZA, V. C. et al. Conhecendo os professores de geografia de Goiás. UEG. 2005. Disponível em: http://www.prp.ueg.br/06v1/ conteudo/pesquisa/inic-cien/eventos /sic2 005/arquivos/humanas/conhecendo_prof. pdf. Acesso em: 13 agosto 2009.

ZENE, D. T. P. L. Disciplina escolar: meta ou mito? Qual o papel do orientador educacional no contexto da Escola João XXIII. Irati, 2003. Monografia (graduação) - Curso de Licenciatura em Letras - Universidade Estadual do Centro-Oeste, 2003.

Enviado em: 28/05/2010 Aceito em: 01/06/2011 